\title{
Surgical Outcome of Peripheral Vascular Injuries in Adults
}

\author{
Ghazanfar Ali, Ayesha Shaukat, Somer Masood, Abdul Ghaffar and Khalid Masud Gondal \\ Department of West Surgical Ward, King Edward Medical University, Mayo Hospital, Lahore, Pakistan
}

\begin{abstract}
Objective: To describe the management and outcome of adult patients after peripheral vascular injuries.

Study Design: Observational study.

Place and Duration of Study: Accident \& Emergency Department, Mayo Hospital Lahore, Pakistan, from January 2014 to December 2018.

Methodology: All adult trauma patients (aged $\geq 13$ years), who were admitted following injury to peripheral blood vessels regardless injuries, were included. Variables including patient data, mechanism of injury, vessel involved, injury severity score (ISS), surgical procedure etc. were retrospectively extracted from patient charts. Binary logistic and multinomial regression analyses were performed. The $p$-value $<0.05$ was considered significant for mortality and limb outcome.

Results: There were 117 patients, with mean age of $28.9 \pm 11.6$ years. The commonest cause was blunt trauma (55.6\%). The popliteal artery was most commonly involved (44.4\%). Complete transection of artery was the most common type of injury (58.1\%). The mean ISS was $17.2 \pm 10$. Reverse saphenous vein graft (RSVG) was the most common surgical repair (49.6\%) procedure. Wound infection $(17.1 \%)$ was the main complication. Limb salvage rate was $73.5 \%$ and mortality rate was $5.1 \%$. Variables significantly influencing the limb outcome (amputated vs. salvaged) were duration of injury ( $p<0.001)$, concomitant body injury ( $p=0.009)$, ISS ( $p<0.001)$, surgical procedure $(p<0.001)$, hemoglobin on presentation $(p<0.001)$, number of blood transfusion $(p=0.05)$ complications after surgery $(p<0.001)$ and referral or not $(p=0.001)$. Factors significantly associated with mortality were duration of injury $(p=0.008), I S S(p=$ $0.002)$ and complications after surgery $(p=0.011)$.

Conclusion: Low hemoglobin on presentation, postoperative increased requirement of blood transfusions and having reverse saphenous graft as procedure were independent risk factors for amputation. ISS score and postoperative complications led to higher amputation and mortality rates after surgery.
\end{abstract}

Key Words: Injury severity score (ISS), Glasgow coma scale (GCS), Reverse saphenous graft (RSVG), Fasciotomy, Popliteal artery, Mortality.

How to cite this article: Ali G, Shaukat A, Masood S, Ghaffar A, Gondal KM. Surgical Outcome of Peripheral Vascular Injuries in Adults. J Coll Physicians Surg Pak 2020; 30(08):839-843.

\section{INTRODUCTION}

Peripheral vascular injuries are one of major causes of mortality and morbidity worldwide. Extensive hemorrhage after injury is perhaps the most significant and preventable cause of death after injury, ${ }^{1,2}$ while ischemic tissue damage leads to high rates of amputation in a characteristically young and active population. ${ }^{3}$ In third world countries, traumatic vascular injury poses a major healthcare problem forpatientmanagement. ${ }^{4}$

In urban trauma centres, extremity vascular injuries account for $\sim 5 \%$ of all major trauma presentations. ${ }^{5}$ Some studies suggest femoral artery ${ }^{6}$ to be the most common vessel involved; however, recent studies also suggested popliteal artery, ${ }^{7}$ and other study suggested brachial artery involvement, ${ }^{8}$ to be the most common.

Correspondence to: Dr. Ghazanfar Ali, Department of West Surgical Ward, King Edward Medical University / Mayo Hospital, Lahore, Pakistan

E-mail:dr.gznfr@gmail.com

Received: April 20, 2020; Revised: July 22, 2020;

Accepted: August 21, 2020

DOI: https://doi.org/10.29271/jcpsp.2020.08.839
There is variation in literature regarding most common mode of presentation; however, studies done in subcontinent showed blunt trauma to be most common cause of injury. ${ }^{4,7}$

Teixeira et al. suggested that lower limit must prevail for execution of prophylactic fasciotomies - especially in the lower limbs and with prolonged ischemia, considerable resuscitation needs, or accompanying musculo - skeletal injury. ${ }^{1}$ Khan et al. reported limb salvage rate as 41 percent, while death rate was 5.48 percent after peripheral vascular damage. In their results, the main cause of limb impairment was delay in presentation over more than 8 hours of injury. ${ }^{4}$ Gopinathan et al. in their analysis found blunt trauma to be more frequent type of vascular injury and ability to save limb was present in $43.2 \%$ when the patient reported within 12 hours of injury. ${ }^{7}$

Very limited studies have been conducted in Pakistani where lack of knowledge of traffic laws, rash driving and under developed infrastructure are still the predominant causes of road traffic accidents presenting in emergency department. There is a very small number of qualified vascular surgeons in Pakistan, so training of general surgeons in vascular surgery is very important. 
Table I: Multinomial regression analysis of variables associated with limb and patient outcome.

\begin{tabular}{|c|c|c|c|c|}
\hline Patient variables & $\begin{array}{c}\text { Multivariate analysis ORs }(95 \% \mathrm{Cl}) \\
\text { Limb outcome } \\
\text { (Amputated vs. Salvaged) }\end{array}$ & $P=\leq 0.05$ & $\begin{array}{c}\text { Multivariate analysis ORs }(95 \% \mathrm{Cl}) \\
\text { Patient outcome } \\
\text { (Discharged vs. Died) }\end{array}$ & $P=\leq 0.05$ \\
\hline Duration of injury & $0.203(0.133-0.363)$ & $<0.001$ & $0.252(0.090-0.703)$ & 0.008 \\
\hline Concomitant body injury & $0.332(0.146-0.759)$ & 0.009 & $0.264(0.053-1.308)$ & 0.103 \\
\hline injury severity score (ISS) & $1.135(1.077-1.195)$ & $<0.001$ & $1.261(1.087-1.462)$ & 0.002 \\
\hline Surgical procedure & $0.364(0.233-0.569)$ & $<0.001$ & $0.871(0.423-1.793)$ & 0.708 \\
\hline Hemoglobin on presentation & $0.255(0.129-0.502)$ & $<0.001$ & $0.280(0.075-1.049)$ & 0.059 \\
\hline Blood transfused in $<24$ hours & $0.529(0.367-0.762)$ & 0.001 & $0.501(0.239-1.049)$ & 0.067 \\
\hline Complication after surgery & $1.773(1.426-2.204)$ & $<0.001$ & $1.695(1.126-2.552)$ & 0.011 \\
\hline Referred patient or not & $4.617(1.851-11.552)$ & 0.001 & $5.882(0.665-51.988)$ & 0.111 \\
\hline
\end{tabular}

Endovascular choices are still restricted in resource-poor countries and open methods are still favoured technique in our institution. Audit of current practices is important to evaluate our daily practices against established procedures; hence, continuously improve the techniques.

In addition, there is a need to search at the causes responsible for the amputations and fatalities following extremity vascular injuries.

The main objective of this study was to investigate the presentation, management and outcome of patients after traumatic peripheral vascular injuries presented to tertiary care hospital of Lahore, Pakistan.

\section{METHODOLOGY}

A retrospective observational study for the period January 2014 to December 2018 was conducted. Patients with peripheral traumatic vascular injury presented to Department of Accident and Emergency (A\&E) at Mayo Hospital, Lahore, Pakistan were inducted retrospectively. Research analysis was based on patient-level data extracted after approval from the Institutional Review Board and Ethical Committee. A Performa was formulated signifying all relevant data to be retrieved from medical records. Postgraduate residents of Surgery Department teamed up as data retrievers and they were debriefed before data abstraction. During their procedure, they were supervised by one of the study investigators; however, blind to the outcome of the study. Data sampling was conducted using a convenience style with a pre-determined duration of five years. Those charts showing missing values in any of the variables were deleted from study. Patient charts examined and all those patients, whose record showed age $\geq 13$ years, having injury to peripheral blood vessels with or without soft tissue and orthopedic injuries were included. Patients whose record showed injuries to neck, heart and intra-cranial vessels, facial vessel injuries, abdominal and pelvic major vessels, iatrogenic vascular injuries and injuries below knee/elbow joint were excluded.

Patient's demographics include age and gender, referral case, Glasgow coma scale, mechanism of injury, time to reach hospital, vessels involved, type of injury, associated extremity injury and concomitant body injury. ISS, surgical procedures and interventions, adjuvant procedures, need of fasciotomy, hemoglobin on presentation, blood transfused in $<24$ hours, complications, length of hospital stay, limb salvage rate, amputation rate and mortality were other factors.

Statistical analysis carried out with the statistical package for social sciences version 26 software. The number variables e.g. age, GCS, ISS etc. expressed as means and standard deviations, categorical data like gender, mechanism of injury, type of surgery, complication etc. as frequency and percentage. Continuous variables compared using the Student's t-test and categorical variables by using Chisquare/Fischer's Exact test. The $p$-values of $\leq 0.05$ considered significant. When assessing the limb loss, binary logistic regression analysis performed calculating odds ratio (OR), 95\% confidence interval $(\mathrm{Cl})$ and $p$-value $\leq 0.05$. After that, multinomial regression analysis calculating odds ratio (OR), $95 \%$ confidence interval $(\mathrm{Cl})$ and $p$-value $\leq 0.05$ of variables associated for limb and patient outcome performed.

\section{RESULTS}

One hundred and seventeen patients had vascular extremity injuries over the last five years who fulfilled the selection criteria. The main outcome were limb salvage $n=86(73.5 \%)$ vs. amputated $n=31$ (26.5\%) and discharged $n=111$ (94.9\%) vs. died $n=6(5.1 \%)$. There were $109(93.2 \%)$ males and eight $(6.8 \%)$ females, with mean age at presentation was $28.9 \pm 11.6$ years. The mean GCS on presentation was $12.05 \pm 1.94$. Out of $117,61(52 \%)$ cases belonged to local city population and $56(48 \%)$ were referred cases from small cities. Presentation time $(p<0.001)$ was variable with eight patients $(6.8 \%)$ presented to hospital in $<30$ minutes, 27 $(23.1 \%)$ in 30 minutes to an hour, $28(23.9 \%)$ in $1-3$ hours, $23(19.7 \%)$ in 3-6 hours, $16(13.7 \%)$ in $6-12$ hours and 15 $(12.8 \%)$ presented after more than 12 hours.

Regarding the mechanism of injury $(p=0.472)$, the most 
common cause was blunt trauma ( $n=65,55.6 \%$ ) followed by penetrating trauma including gunshot injuries $(n=24$, $20.5 \%)$ and sharp object injuries $(n=28,23.9 \%)$. Among vessels injured $(p=0.001, p=0.085)$, popliteal artery was most commonly injured $(n=52,44.4 \%)$, followed by brachial $(n=41,35.0 \%)$ and femoral artery $(n=24,20.5 \%)$. Concomitant body injuries $(p<0.001)$ were present in $(n=84,71.8 \%)$. In surgical procedure $(p<0.001,0.766)$, reverse saphenous graft was commonest procedure done $(n=58,49.6 \%)$, followed by primary anastomosis $(n=40,34.2 \%)$, primary empirical amputation $(n=16,13.7 \%)$ and embolectomy $(n=3,2.6 \%)$. Postoperative complications were significantly associated with both limb and patient outcome $(p<0.001)$, wound infection being commonest complication $(n=20$, $17.1 \%)$.

Regarding type of injury ( $p$ value $=0.176, p=0.603$ ), complete transection was most common type of injury $(n=68,58.1 \%)$ followed by partial transection $(n=33$, $28.2 \%)$, intimal tear $(n=10,8.5 \%)$ and arterial spasm $(n=6$, $5.1 \%)$. Associated extremity injuries ( $p=0.001, p=0.873$ ) were most commonly soft tissue associated with bony fracture $(n=46,39.3 \%)$, simple soft tissue injury $(n=34,29.1 \%)$, soft tissue associated with fracture and venous injury $(n=20$, $17.1 \%)$, soft tissue with vein injury $(n=6,5.1 \%)$. Others were soft tissue along with bony fracture and nerve injury $(n=4$, $3.4 \%)$, soft tissue along with bony fracture, nerve and venous injury $(n=4,3.4 \%)$, soft tissue along with nerve and venous injury $(n=3,2.6 \%)$. Injury Severity Score (ISS) calculated by checking patient record and looking into other body injuries with mean value of $(14.0 \pm 5.99$ vs. $25.90 \pm 13.37$ $p<0.001$ and $15.98 \pm 8.81$ vs. $38.83 \pm 5.19 p<0.001)$.

In adjuvant extremity surgery $(p<0.001, p=0.535)$, record showed simple debridement of the devitalised tissue in $(n=47,40.2 \%)$, external fixator and vein ligation in $(n=22$, $18.8 \%)$ and vein ligation in $(n=16,13.7 \%)$. External fixator without other intervention $(n=13,11.1 \%)$, nerve repair $(n=10,8.5 \%)$, external fixator + vein repair + nerve repair $(n=4,3.4 \%)$ and simple POP cast application $(n=2,1.7 \%)$ were observed. Sixty-one (52.14\%) patients had limb fasciotomy due to compartment syndrome $(p=0.185, p>0.999)$. The hemoglobin on presentation $(p<0.001, p=0.062)$ was in the range of $8-9 \mathrm{~g} / \mathrm{dl}$ in $(\mathrm{n}=54,46.2 \%)$ patients, $10-12 \mathrm{~g} / \mathrm{dl}$ in $(n=33,28.2 \%),<8 \mathrm{~g} / \mathrm{dl}$ in $(\mathrm{n}=26,22.2 \%)$ and $>12 \mathrm{~g} / \mathrm{dl}$ in $(n=4,3.4 \%)$. The blood transfusion requirement in $<24$ hours $(p<0.001, p=0.051)$ were 2 pints in $(n=30,25.6 \%)$ patients, 3 pints in $(n=27,23.1 \%), 4$ pints in $(n=25,21.4 \%)$, 1 pint in $(n=21,17.9 \%)$ and $>5$ pints in $(n=1412 \%)$. The mean duration of hospital stay was (10.95 \pm 3.54 vs. $12.10 \pm 4.75 p=0.164$ and $11.23 \pm 3.76$ vs. $11.83 \pm 6.55 p=$ $0.712)$.

The limb salvage rate was $(n=86,73.6 \%)$; however, in those limbs could not be saved on first application, empirical amputation of the limb was performed in $(n=16,13.6 \%)$ cases and secondary amputation in $(n=15,12.8 \%)$ cases. The discharge rate was $(n=111,94.9 \%)$ while $(n=6,5.1 \%)$ patients died after peripheral vascular injuries.

Against all variables, a binary logistic regression for limb outcome performed calculating odd ratios (ORs) with $95 \%$ confidence interval maintaining cut off $p$-value $(\leq 0.05)$. Independent variables who had significant $p$-value were duration of injury ( $p<0.001)$, ISS ( $p<0.001$ ), concomitant body injury $(p=0.009)$, surgical procedure performed ( $p<0.001)$, hemoglobin on presentation ( $p<0.001$ ). Blood units transfused in less than 24 hours ( $p$ value $=0.001$ ), post-op complications ( $p$ $<0.001$ ) and whether patient was referred or from local population ( $p$ value $=0.001$ ) were other significant variables.

A multinomial regression analysis performed on those variables that had significant values in binary regression analysis to see those associated with limb and patient outcome. Odd ratios (ORs) calculated with 95\% confidence interval and maintaining cut off $\leq 0.05$. Significant variables influencing limb outcome (amputated vs. salvaged) were duration of injury concomitant body injury, ISS, surgical procedure, $\mathrm{Hb}$ on presentation, number of blood transfusion, complications after surgery and referral or not. Just three important variables were correlated with the outcome of the patient (discharged vs. died) i.e. duration of injury, ISS and complications after surgery (Table I).

\section{DISCUSSION}

Vascular injury patients present in major trauma centres around the world almost daily. ${ }^{8}$ Peripheral vascular trauma is one of the major causes of morbidity and mortality in hospital and developing nations, still lacks public knowledge and laws on road traffic to avoid injury and its outcome. ${ }^{4}$ Mostly patients present within the young and adolescent age, ${ }^{9}$ which is similar to our study. It has been observed that multidisciplinary team (MDT) clinical assessment to traumatic injuries is associated with improved morbidity and decreased in-hospital mortality. ${ }^{10,11}$

Western studies indicate mechanism of injury is mostly penetrating trauma; stab and gunshot wounds are by far the most common causes. ${ }^{12-14}$ However, mechanism of injury differs in different parts of the world. ${ }^{4,7}$ In our research, however, blunt trauma (road traffic accidents) was the most common presentation mode comparable to some subcontinent studies. ${ }^{4,7}$ Some studies have reported limb salvage rate of around $95 \%$ after vascular repair, if timely performed in uncomplicated penetrating arterial injury. ${ }^{15,16}$ Limb salvage is less successful after blunt trauma than penetrating trauma ${ }^{17}$ and blunt extremity vascular injuries mentioned by Usman et al. may be complicated and generally linked with elevated mortality and complication rates including significant amputation regardless of whether the upper or lower extremity is involved; ${ }^{9}$ however, the present research could not validate that point. 
Limb salvage is critically dependent on ischemic time. ${ }^{18}$ The amputation rate was significantly reduced when ischemic time was $<6$ hours. Alarhayem et al. described time span between injury and restoration of perfusion to the injured limb is key factor in determining outcome; ${ }^{19}$ that was noted in this study as well. In the present study, most of the time patients were local city population. However, patients from far-flung areas were referred to the hospital from peripheral smaller hospitals and amputation and death were more common in those referred cases.

In addition, it is suggested that pre-hospital tourniquet use leads to improved outcomes in extremity vascular trauma. ${ }^{20}$ Cone et al. in their study, showed that early fasciotomy leads to limb salvage in traumatic extremity injury and in our study, fasciotomy rate was around $52.1 \%{ }^{21}$

Preoperative CT angiography is a benchmark for diagnosing vascular extremity injury. ${ }^{22}$ Yet, in the presence of hard signs of vascular trauma, patients must be rushed to operation theatre and external bleeding from the extremity should be controlled as soon as possible. ${ }^{23}$

In this research, the most common artery injured was popliteal artery, which correlates with other studies. ${ }^{7}$ Onakpoya et al. showed complete transection of artery to be the most common form of arterial injury of extremity, ${ }^{24}$ and this study showed the same result. Multiple scoring systems are used to assess the trauma patients, the authors used ISS and this study showed a not so good outcome with higher score as in other studies.

Regarding surgical repair, the most commonly performed procedure in this study was reverse saphenous vein graft (RSVG) consistent with other studies; ${ }^{4}$ and surgical procedure was risk factor for amputation but not for mortality. Temporary shunting of vessels was done with routine caliber nelaton catheter to buy time for final repair; however, neither synthetic graft nor endovascular procedures were used due to limited resources.

This study showed that patients who had increased $(>5)$ requirement of postoperative blood transfusion led to more chances of limb loss also those who had complication after surgery were more prone to amputation and life loss. The mean length of stay in hospital in our study was $11.3 \pm 4$ days; however, its association with both outcomes was insignificant. The limb salvage rate was around $73.5 \%$ and combined primary and secondary amputations rate was $26.5 \%$. Mortality rate was $5.1 \%$. The main goals in controlling vascular injury are prompt reduction of hemorrhage and quick recovery to blood flow.

This research has drawbacks regarding unavailability of endovascular treatment in emergencies; hence, long-term results could not be reported due to the patients' poor follow-up record. More research needed to validate the findings of this research, and more vascular surgeons are encouraged to be trained in smaller cities to reduce referral rates to major cities and improve the outcome. Amid such shortcomings, the outcomes of management of such injuries in this hospital were close to those described in the literature.

\section{CONCLUSION}

Peripheral vascular trauma is the most common part of a polytrauma that involves the multidisciplinary trauma team comprising multiple clinicians to conduct a broad variety of procedures simultaneously, such as vascular repair and reconstructive orthopedics. Peripheral vascular injuries are frequently ignored and most cases are received at late stage of complications despite the clear clinical signs, perhaps due to shortage of professional human resources. The treatment of these injuries poses a variety of difficulties due to technical backwardness in developing countries. The delivery of adequate treatment is a crucial factor for patient survival and limb recovery.

\section{ETHICAL APPROVAL:}

Ethical approval was taken from the competent authority.

\section{PATIENTS' CONSENT:}

Informed consents were obtained from all individual participants included in the study.

\section{CONFLICT OF INTEREST:}

Authors declared no conflict of interest.

\section{AUTHORS' CONTRIBUTION:}

GA: Concept, design, interpretation, draft.

AS: Drafting, critical analysis, final approval.

SM: Occupant, critical analysis, final approval.

AG: SPSS, acquisition of data drafting.

KMG: Design, critical analysis, final approval.

\section{REFERENCES}

1. Teixeira PG, DuBose J. Surgical management of vascular trauma. Surg Clinic N Am 2017; 97:1133-55.

2. Gruen RL, Jurkovich GJ, McIntyre LK, Foy HM, Maier RV. Patterns of errors contributing to trauma mortality: Lessons learned from 2594 deaths. Ann of Surg 2006; 244(3): 371-80. doi: 10.1097/01.sla.0000234655.83517.56.

3. Rozycki GS, Tremblay LN, Feliciano DV, McClelland WB. Blunt vascular trauma in the extremity: Diagnosis, management, and outcome. J Trauma 2003; 55(5):814-24. doi: 10.1097/01.TA.0000087807.44105.AE.

4. Khan FH, Yousuf KM, Bagwani AR. Vascular injuries of the extremities are a major challenge in a third world country. J Trauma Manag Outcomes 2015; 9:5. doi: 10.1186/s13032015-0027-0.

5. Sciarretta JD, Perez-Alonso AJ, Ebler DJ, Mazzini FN, Petrone P, Asensio-Gonzalez JA. Popliteal vessel injuries: Complex anatomy, difficult problems and surgical challenges. Eur J Trauma Emerg Surg. 2012; 38(4):373-91. doi: 10.1007/ 
s00068-012-0217-7.

6. Ball CG. Penetrating nontorso trauma: the extremities. Can J Surg 2015; 58(4):286-8. doi: 10.1503/cjs.005815.

7. Gopinathan NR, Santhanam SS, Saibaba B, Dhillon MS. Epidemiology of lower limb musculoskeletal trauma with associated vascular injuries in a tertiary care institute in India. Indian J Orthop 2017; 51(2):199. doi: 10.4103/ 0019-5413.201702.

8. Feliciano DV. For the patient-Evolution in the management of vascular trauma. J Trauma Acute Care Surg 2017; 83(6):1205-12. doi: 10.1097/TA.0000000000001689.

9. Usman R, Jamil M, Anwer MF. Evaluation, surgical management and outcome of traumatic extremity vascular injuries: A 5-year Level-1 trauma centres experience. Ann Vasc Dis 2018; 11(3):312-7. doi: 10.3400/avd.oa.18-00068.

10. D'Alessio I, Domanin M, Bissacco D, Romagnoli S, Rimoldi P, Sammartano $\mathrm{F}$, et al. Operative treatment and clinical outcomes in peripheral vascular trauma: The combined experience of two centers in the endovascular era. Ann Vasc Surg 2020; 62:342-8. doi: 10.1016/j.avsg.2019.06.037. Epub 2019 Aug 23.

11. Cooper N, Roshdy M, Sciarretta JD, Kaufmann C, Duncan S, Davis J, et al. Multidisciplinary team approach in the management of popliteal artery injury. J Multidiscip. Healthc 2018; 11:399. doi: 10.2147/JMDH.S151498.

12. Eslami MH, Saadeddin ZM, Rybin DV, Avgerinos ED, Eslami PW, Siracuse JJ, et al. Trends and Outcomes of Pediatric Vascular Injuries in the United States: An Analysis of the National Trauma Data Bank. Ann Vasc Surg 2019; 56:52-61. doi: 10.1016/j.avsg.2018.09.006.

13. Sugrue M, Caldwell EM, D'Amours SK, Crozier JA, Deane SA. Vascular injury in Australia. Surg Clinics 2002; 82(1):211-9. doi: 10.1016/s0039-6109(03)00150-6.

14. Barmparas G, Inaba K, Talving P, David JS, Lam L, Plurad D, et al. Pediatric vs adult vascular trauma: A National Trauma Databank review. J Pediatr Surg 2010; 45(7):1404-12. doi: 10.1016/j.jpedsurg.2009.09.017.

15. Topal AE, Eren MN, Celik Y. Lower extremity arterial injuries over a six-year period: Outcomes, risk factors, and management. Vasc Health Risk Manag 2010; 6:1103. doi: 10.2147/VHRM.S15316.

16. Kohli A, Singh G. Management of extremity vascular trauma: Jammu experience. Asian Cardiovasc Thorac Ann 2008; 16(3):212-4. doi: 10.1177/021849230801600307.

17. Vielgut I, Gregori M, Holzer LA, Glehr M, Hashemi S, Platzer $P$, et al. Limb salvage and functional outcomes among patients with traumatic popliteal artery injury: A review of 64 cases. Wien Klin Wochenschr 2015; 127(14):561-6. doi: 10.1007/s00508-015-0715-9.

18. Qi F, Li J, Qi X, Xiao LW. Comprehensive analysis of the ischemic times of main artery injury in the limbs. Zhongguo gu shang 2015; 28(10):932-5.

19. Alarhayem AQ, Cohn SM, Cantu-Nunez O, Eastridge BJ, Rasmussen TE. Impact of time to repair on outcomes in patients with lower extremity arterial injuries. J Vasc Surg 2019; 69(5):1519-23. doi: 10.1016/j.jvs.2018.07.075.

20. Smith AA, Ochoa JE, Wong S, Beatty S, Elder J, Guidry C, et al. Prehospital tourniquet use in penetrating extremity trauma: Decreased blood transfusions and limb complications. J Trauma Acute Care Surg 2019; 86(1):43-51. doi: 10.1097/TA.0000000000002095.

21. Cone J, Inaba K. Lower extremity compartment syndrome. J Trauma Acute Care Surg 2017; 2(1):e000094. doi: 10.1136/tsaco-2017-000094. eCollection 2017.

22. Madhuripan N, Mehta P, Smolinski S, Njuguna N. Computed tomography angiography of the extremities in emergencies. Semin Ultrasound CT MR 2017; 38(4):357-69. doi: 10.1053/j.sult.2017.03.001.

23. Tanga C, Franz R, Hill J, Lieber M, Galante J. Evaluation of experience with lower extremity arterial injuries at an urban trauma center. Int J Angiol 2018; 27(1): 29-34. doi: 10.1055/s-0037-1618570.

24. Onakpoya UU, Eyekpegha JO, Ogunrombi A, Ohuche AS, Ojo TO. Pattern of extremity arterial injury and outcome of repair in Southwest, Nigeria. Niger J Surg Sci 2019; 25(1):85. doi: 10.4103/njs.NJS_18_18. 